\title{
Effects of Simulation-based Education Combined Team-based Learning on Self-directed Learning, Communication Skills, Nursing Performance Confidence and Team Efficacy in Nursing Students
}

\author{
Ko, Eun ${ }^{1)} \cdot$ Kim, Hye Young ${ }^{2)}$
}

\begin{abstract}
1) Department of Nursing, College of Life Science and Natural Resources, Sunchon National University, Suncheon 2) College of Nursing, Research Institute of Nursing Science, Chonbuk National University, Jeonju, Korea
\end{abstract}

\begin{abstract}
Purpose: The purpose of this study was to identify the effects simulation-based education combined team-based learning (SBE combined TBL) compared to simulation-based education (SBE) on undergraduate nursing students. Methods: A non-equivalent control group design with pre-and posttest measures was used. The participants in the study were 181 students. The SBE combined TBL group consisted of 84 senior students in 2013, and the SBE group consisted of 97 seniors in 2014. Collected data were analyzed using chi-square, independent t-test and ANCOVA with the statistical package SPSS 22.0 for Windows. Results: There was a significant improvement in communication skills, nursing performance confidence, team efficacy, and team performance scores in the SBE combined TBL group compared to the SBE group ( $\mathrm{t}=2.45, p=.015 ; \mathrm{F}=4.30, p=.040 ; \mathrm{t}=3.06, p=.003 ; \mathrm{t}=8.77, p<.001)$. However, there was no statistically significant difference in self-directed learning between the groups. Conclusion: SBE combined TBL compared to SBE is an effective teaching and learning method to enhance various positive educational outcomes for nursing students. Therefore, we suggest that future studies investigate the development of an integrated course in which team-based learning is applied to theoretical sessions and simulation-based training.
\end{abstract}

Key Words: Patient simulation, Learning, Nursing students

Received August 29, 2016 Revised November 5, 2016 Accepted January 31, 2017

Corresponding author: Kim, Hye Young

College of Nursing, Research Institute of Nursing Science, Chonbuk National University

567 Baekje-daero, deokjin-gu, Jeonju 54896, Korea

Tel: +82-63-270-4618, Fax: +82-63-270-3127, E-mail: tcellkim@jbnu.ac.kr 


\section{INTRODUCTION}

\section{Background}

Nursing education aims to train nurses who are professionals with core competencies required for nursing field and for this purpose, education is being provided in classroom and clinical field. As students learn applicability of knowledge, skills and attitude learned from classroom through a practicum in clinical field, as clinical practice education plays a key role in nursing education. However, the field of clinical practice has changed very rapidly so that it is difficult to predict or control the environment of clients and the health care awareness of clients is heightened and the demand for high-quality nursing service and its right increases so that it is a situation that it is difficult for students to have a clinical practice [1]. Therefore, simulation-based education (SBE) is used to reproduce various clinical situations as a way to complement these restrictive situations and effectively improve students' practice.

SBE is an effective education strategy to achieve the goal of nursing education [1]. In particular, SBE using high-fidelity simulators or standardized patients (SP) has been widely used in nursing education. Over the past decade, many studies have been conducted on the effectiveness of SBE in domestic nursing and SBE has been associated with positive learning outcomes in areas of psychomotor, cognition, and affection among students [2,3]. There is a difference in effect size among the three areas and the psychomotor area is the largest and the affective area is the smallest [2] Also, when it comes to measurement variables for each area, clinical performance ability is commonly used in the psychomotor area, knowledge and problem solving ability in the cognition area, satisfaction and selfefficacy in the affection area [2,3]. It is known that clinical performance ability, clinical judgment and self-confidence, etc. have a large effect while self-directed learning and critical thinking, etc. have a small effect [2]. Therefore, a new strategy to maximize the efficiency and efficacy of SBE needs to be designed. There are also a few studies linking problem-based learning (PBL) to SBE education and the study result showed that although it was effective for problem solving [4,5], and for student self-confidence [5], it was not statistically significant for communication and self-directed learning [4].

Today, nursing organizations are involved in team nursing, and each team member should be able to effectively carry out his or her role, assuming that all team members work together to achieve a common goal., Therefore, a variety of knowledge and competencies such as leadership, communication skills, organizational skills, clinical competency, and self-directed learning are required for effective nursing [6]. Furthermore, when outcomes of nursing education program are being presented by the Korean Accreditation Board of Nursing Education (KABONE), in order to transform students into nurses equipped with nursing professional capacities required in domestic and global settings, the role of nurses in the nursing team is being emphasized.

Team-based learning (TBL) is an education strategy based on a team system where members share a vision, build an efficient communication system, interact with each other, and achieve goals [7]. It is different from the general small group discussion in that it utilizes the team's learning ability in order to improve performance., i.e., it involves a problem-solving process based on cooperation among team members [8]. Generally small group learning is a teaching and learning strategy that can create synergies of learning by using each member as a learning resource through role playing in accordance with the learner's abilities and skills, the ambiguity of learning outcomes, the inconsistency of the inter-tutor evaluation, and the level of inter-tutor intervention in addition to negative perceptions such as free riding, etc. are being pointed out as disadvantages [9]. TBL is a teaching learning method that allows feedback through individual learning, cooperative learning, and mini lectures by teachers. TBL can be an alternative to complement the disadvantages of existing small group discussions by providing clearer learning directions to students and encouraging active student participation through quizzes on learning contents and it has a positive impact on learning activities such as communication, leadership, and team collaboration compared to existing small group discussions [10]. TBL will be used so that students learn to organize themselves in teams and cooperate with each other to solve the diverse nursing problems that arise when caring for patients. Recently, in nursing education, when it comes to some studies using TBL, there were studies which were only applied in theoretical subjects, but no study was applied in the practical class and most of the studies were single-group studies without a control group [10-13]. The results of previous studies have shown that students' self-directed learning $[12,13]$, problem solving [13], learning motivation [10,12] and academic achievement [11] have increased. Therefore, in this study there was an attempt to link TBL [7] to SBE education which is an educational strategy to increase interaction with between students.

Some studies have been conducted in general smallgroup simulations so far, and in most studies the com- 
petence of individual learners have been evaluated rather than group competence when confirming the effectiveness of the education $[14,15]$. The aim of this study was to identify self-directed learning, communication skills, nursing performance confidence and team-efficacy which are identified as a positive learning effect of $S B E$ and TBL based on Jeffries' nursing education simulation model [16] and Michaelsen et al.,'s TBL model [7]. The simulation-based education combined team-based learning (SBE combined TBL) was applied to nursing students and its effectiveness was compared against that of the simulation-based education (SBE). The effect of these two types of simulation education was to compare them and help to design more effective simulation education.

\section{Aim}

This study intends to compare the effect of the SBE combined TBL and SBE on undergraduate nursing students' self-directed learning, communication skills, nursing performance confidence, team efficacy, and team performance scores. The specific objectives are as follows.

- To compare the self-directed learning of SBE combined TBL group and SBE group.

- To compare the communication skills of SBE combined TBL group and SBE group.

- To compare the nursing performance confidence of SBE combined TBL group and SBE group.

- To compare team efficacy of SBE combined TBL group and SBE group.

- To compare the team performance scores of SBE combined TBL group and SBE group.

\section{METHODS}

\section{Study Design}

This was a quasi-experimental study using a non-equivalent control group pretest-posttest design.

\section{Study Participants}

The participants in this study were senior nursing students, who took a simulation integrated training course in the first semester of either 2013 or 2014 at a college of nursing in G city. This study was carried out from March to April in 2013 and 2014 in the simulation integrated education course. The SBE combined TBL group consisted of the senior students in 2013, and the senior students in 2014 were assigned to the SBE group. The reason for the 2-year time lag between the SBE combined TBL group and the SBE group in this study was to reduce the diffusion effect that might occur if the experimental procedures were performed at the same time. In addition, since previous experience in classroom or clinical practice, learning environment, etc. may affect the results of this study, the same year students of one university were investigated to ensure homogeneity between the two groups.

From the students, excluding those who had experienced SBE or TBL before, 86 students from the SBE combined TBL group and 98 from SBE group voluntarily participated in this study. In the SBE combined TBL group, 86 students participated out of 89 students except one transfer student with SBE experience and in the SBE group, 98 students out of 100 students participated.

To determine the sample size, G*Power 3.1.3, a statistical power calculation program based on Cohen's sampling formula was used. As a result of calculating with a two-tailed significant level of .05 for independent t-test, a medium effect size $(\mathrm{d}=.50)$, and a statistical power of .80 , the minimum sample size for each group was 64 . For the final data analysis, excluding three surveys with insufficient answers, data from 84 participants in the SBE combined TBL group and 97 in the SBE group were utilized.

\section{Instruments}

\section{1) Self-directed learning}

Self-directed learning was assessed using a tool that Lee, Chang, Lee, and Park [17] developed to assess self-directed learning in college students and adults. This tool was developed by the Korean Education Development Institute (KEDI) to diagnose life skills of Koreans by reflecting the OECD's adult literacy and life skills and the needs of Korean society. It consists of 45 questions, with ten questions on learning desire, five on goal setting, five on education resource analysis, five on basic self-control ability, five on learning strategy, five on consistency of learning, five on factors of the result, and five on self-searching. The answer to each question is based on a five-point Likert scale, from 1 meaning "very rarely" to 5 meaning "very frequently", with a higher score indicating better self-directed learning. At the point of development of the instrument internal reliability was assessed, obtaining a Cronbach's $\alpha$ of .93 [17], and in this study a value of .92 was obtained.

\section{2) Communication skills}

Communication skills were assessed using the instrument that Lee, Chang, Lee, and Park [17] developed to as- 
sess communication skills in college students and adults. This tool was developed by KEDI to diagnose the life skills of Koreans by reflecting the OECD's adult literacy and life skills and the needs of Korean society. It consists of 49 questions, with seven questions on information gathering, seven on attentive listening, seven on overcoming stereotype ideas, seven on open communication, seven on selfexpression, seven on driven communication, and seven on understanding other's standpoint. The answer to each question was based on a five-point Likert scale, from 1 meaning "very rarely" to 5 meaning "very frequently", with a higher score indicating better communication skills. At the point of development of the instrument, internal reliability was assessed, obtaining a Cronbach's $\alpha$ of .80 [17] and in this study a value of .88 was obtained.

\section{3) Nursing performance confidence}

Nursing performance confidence was assessed using the instrument that Yang and Park [18] developed. It consists of 19 questions, with four questions on the application of nursing process, four on conducting direct nursing medication, three on socio-psychological nursing, three on patient education, three on basic nursing conduct, and two on physical assessment and patient monitoring. Before the tool was used, the content of the questions was revised according to the simulation situation of this study and two professors of fundamentals of nursing and two adult nursing professors conducted a content validity test on each item and the results showed that the content validity index of all the questions was .60 or more. The answer to each question was based on a five-point Likert scale, from 1 meaning "very rarely" to 5 meaning "very frequently", with a higher score indicating a higher level of confidence in nursing performance. At the point of development of the instrument, internal reliability was assessed, obtaining a Cronbach's $\alpha$ of .86 [18], and in this study a value of .93 was obtained.

\section{4) Team efficacy}

Team efficacy was assessed using the instrument that Marshal [19] developed, and Kwon [20] translated into Korean. Team efficacy is a shared belief among team members that they can successfully perform a team task, and this tool consists of questions that measure the degree to which a team member expects his or her team to be able to do well with team tasks or team activities. Facial validity test was conducted by two nursing professors who had experience of various cooperative learning based on the team before use of tool and all questions were found to be valid. It consists of eight questions in total., on a five-point
Likert scale, from 1 meaning "very rarely" to 5 meaning "very frequently", with a higher score indicating higher team efficacy. In Marshall's study [19], internal reliability was assessed, obtaining a Cronbach's $\alpha$ of .89 , and in this study a value of .94 was obtained.

\section{5) Team performance score}

The team performance score was evaluated by using a checklist developed by our team. The team performance checklist consists of 20 questions on nursing actions that must be performed according to the simulation situations. The checklist was designed according to two simulation scenarios. The questions consist of items for evaluating the nursing process according to scenario situations as well as the decision making process for the nursing problem, and teamwork in the emergency situation. Content validity test of team performance questions was performed for two situations by creating an expert group consisting of five nursing professors whose major was fundamental or adult nursing. As a result, the content validity index was above $85 \%$ for 20 questions. Based on the actions performed, scores were given as follows: "Very well" meant two points, "Good" one point, and "Poor or non-performance" zero points. The scores ranged from zero to a maximum of 40 points. One researcher and an adult nursing professor external to the research team evaluated team performance independently, and the mean value of their scores was taken as the final score. Inter-scores reliability was secured by going through a consensus training course on the 2-1-0 score of each tem performance question while watching a recorded simulation video before the evaluation and the inter-scores correlation was .93 .

\section{Study Procedures}

\section{1) Simulation needs analysis}

In order to decide on the theme of SBE, we conducted a simulation needs analysis on nurses with two to three years of clinical experience after graduation and on senior nursing students. To identify simulation needs, a survey was sent to 34 graduated nurses and 18 senior students from the nursing school where the researcher was associated. An e-mail was sent to the graduated nurses including the following questions: "As you started your clinical work, in what areas did you think that there should be more preparation from nursing school training?"; and "From the 20 core nursing skills suggested by the KABO $\mathrm{NE}$, for which items do you think there should be the most extensive preparation during school training?" To the senior students, a survey was handed out with questions in- 
cluding the following: "From the 20 core nursing skills suggested by the KABONE, on which items do you feel the least confident?" and "Which nursing skills do you think you should be trained on more extensively before graduating?" Three descriptive questions were answered in order of priority. In the result of summarizing the contents of answers in order of frequency, graduated nurses answered that trainings for coping with emergencies, surgical patient care, explaining diagnostic tests, interpretation of diagnostic test results and report on patient status are needed and among 20 core nursing skills, more preparation was needed in the following order: cardiopulmonary resuscitation (CPR); monitoring of electrocardiogram (ECG) and oxygen saturation; transfusion; indwelling urethral catheter; and pre- and post-operative care. The answers of senior students were as follows: intravenous (IV) injection; indwelling urethral catheter; and CPR. Therefore, the researchers decided to develop two simulation models that would include the above core nursing techniques.

\section{2) Developing scenarios}

Based on the training needs analysis, researchers developed two scenarios for SBE. The first scenario was a nursing module for a stroke patient, including the skills of preoperative care, transfusion, and indwelling urethral catheter. The second was a module for a myocardial infarction patient complaining of chest pain, including the skills of monitoring ECG and oxygen saturation, IV injection, and CPR. Both scenarios were validated by an ICU chief nurse, an ER chief nurse, a neurosurgeon and an emergency medicine doctor, and were accordingly edited and complemented.

\section{3) Preparation for TBL}

TBL consists of the following steps: learning preparation, learning readiness verification, and application of learning contents [7]. In the learning preparation stage, the reading materials were handed out to the students so that they could prepare ahead. Reading materials were developed in preparation for the TBL class. Self-learning reading materials for the learning preparation were focused on the learning goals of the Korean Academy of Fundamentals of Nursing and Korean Society of Adult Nursing, and summarized the nursing care given to stroke and myocardial infarction patients. Ten multiple-choice readiness assurance test (RAT) questionnaires for each module were developed. The RAT changes from basic concept to complex concept while it goes from 1 to 10 and it's configured from simple situations to complex situations. For example, in module 1 , neurological physical examination, symp- toms due to stroke injuries, nursing care, and complications are configured as key components and in module 2, coronary artery disease, symptoms, diagnosis, electrocardiography, emergency nursing, and percutaneous coronary artery intervention were configured as key components so that 10 multiple choice questions were made for each. After the development of the questions, one professor whose major is basic nursing and another professor whose major is adult with experience in TBL classes validated the developed questions, and these were edited accordingly. Group readiness assurance test (GRAT) and individual readiness assurance test (IRAT) questionnaires consisted of the same questions.

\section{4) Preparation of standardized patients}

Based on the algorithm of the stroke patient nursing module, which would be operated with a hybrid simulation, a scenario for the SP was modeled. The SP were selected and accordingly trained, and were two graduates from the nursing school, with two to three years of clinical experience, one as an ER nurse and the other one as nurse in a neurology ward. SPs of the identical two people were used in the SBE combined TBL group and the SBE group. In first year, the SP training was conducted in two sessions of two hours each. The role of the SP was explained, and training in the simulation scenario and patient script were provided by the researcher. The training was conducted so that the SPs could replicate the language, motor reactions, complaints, and anxieties that a patient with stroke would show. In the second year, it took 1 hour for training and was trained to have the same SP role as the first year.

\section{5) Pretest}

One week prior to SBE combined TBL or SBE, an orientation on SBE combined TBL or SBE was given, and verbal consent for the video recording of the simulation training was obtained. A research assistant distributed the self-report survey and conducted a pre-investigation. The answered surveys were collected anonymously into a box placed at the front of classroom and students were asked to freely leave the room.

\section{6) Simulation running}

Simulation running was conducted in one session of three hours a week, with three sessions per module, making a total of nine hours of class for each module, running for a total of six weeks for each group from March to April. There were three classes in the SBE combined TBL group with 28 29 students per class, and the SBE group had four classes with $24 \sim 25$ students per class. In each class, SBE 
combined TBL and SBE group were run with four to five students in one team, with six to seven teams. Teams were decided by drawing straws. A teaching assistant for simulation participated in the second and third session. Before participation, preparations and correct protocol were taught while watching videos about selected nursing skills. A teaching assistance prepared items for nursing techniques during the second session, monitored students to help them exercise their skills freely in their team and provided feedbacks on the procedure after practice. In the third session, she played a role in organizing the environment before and after the simulation running for each team.

\section{(1) SBE combined TBL}

For the SBE combined TBL class, we provided the preparation reading materials one week before and had the students carry out self-learning before class. The first session was conducted for 3 hours. On the first session, the IRAT and GRAT which consisted of the same questions as IRAT were conducted. The purpose of IRAT was to check in class if the students had done the preparation appropriately. The students individually took the exam for 10 minutes and submitted the answer sheets Then, GRAT was run for 25 minutes, and during the GRAT, members belonging to the same team consulted each other and submitted answers. Afterwards, all students had intergroup discussion for 70 minutes to find correct answer to each question on the RAT. Discussion was preceded in a way that as for the opinion of one team, the rest of teams gave their opinions in favor or against per what was agreed upon in the team's discussion and explained the reason. When opinions were being collected, students were encouraged to improve their communication skills by making logical explanations based on accurate grounds. When presenting the team's opinion, all of the team members were given an opportunity to present one or more times per the order determined. After the entire discussion process of finding answers to the 10 questions, the tutor gave appropriate feedbacks including correct answers for 25 minutes. The team with the highest GRAT score was given a small gift as a positive reward for raising the team-efficacy of each team. Subsequently, scenarios for simulation were provided, and each team discussed among team members what the patient's issue was, how to assess the patient, and what kind of nursing care should be provided. Additionally students also wrote a report of the discussion results.

The second session involved trial and evaluation of the nursing techniques in the module. The second session was conducted for 3 hours. The first module included pre-oper- ative care, transfusion, and indwelling urethral catheter, and the second module, ECG and oxygen saturation monitoring, IV injection, and CPR. Video materials of each technique were provided. The students watched a video for each nursing technique and had free practice time in the team after the tutor showed trials of each technique. Then the students drew straws for the three techniques, and were evaluated on their randomly assigned technique. As per the protocol of KABONE, students were given their evaluation results as either "performed" or "non- performed", meaning pass or fail, and the students who failed were given a second chance.

The third session was simulation training and debriefing and was conducted for 3 hours. The first module was a hybrid simulation, with a standardized patient lying on the bed and a model IV of saline solution being injected into the patient, so that the students were able to perform a transfusion. At the patient's leg side, a model urethral catheter was placed. The second module was conducted with the high-fidelity simulator (Medusim HAL $($ ). Before starting the simulation, the role of each team member was decided by straw drawing. Team members enacted the roles of doctor, nurse $\mathrm{A}$, nurse $\mathrm{B}$, nurse $\mathrm{C}$, and nursing student. Each class was broken into six or seven teams. After deciding the order of trials, each team had some free preparation time for the other team's trial in the laboratory. After the trials were finished, the team moved to a separate lecture room for debriefing, saw video records of the trial., and the students were asked to draft simulation reports according to the prepared questionnaire. After the simulation was completed for all teams, a debriefing was conducted following the steps of description, analysis, and application. Each team was given 15 minutes for the simulation, and 50 minutes for the debriefing.

Students' anxiety during simulation reduces self-efficacy and clinical performance [21]. Therefore, to promote team-efficacy, students were introduced to SP before the start of the simulation so that it allows for a high-fidelity simulator and for students to check the practice environment in advance to reduce the burden and anxiety of students. Also, it was emphasized before the simulation that SP and high-fidelity simulator were treated the same as the actual patient and effective therapeutic communication with patients should be used.

\section{(2) SBE}

The first session was conducted following a general small group learning method. Preparation reading materials were not provided to SBE group students and scenario situations for simulation were provided to them. Students 
had a free discussion with each other in the team for 150 minutes, with access to diverse reference materials on topics including the usual patient's problems in such situations, how to assess the patient, and what caring should be provided to the patient. Discussions among team members led them to freely ask the tutor questions and the tutor to explain the questions. Because discussion and question-and-answer occurred within each team, the questions were not shared with all students. The second and third sessions for the SBE group were conducted in the same way as for the SBE combined TBL group.

\section{7) Posttest}

On the day when the SBE combined TBL or SBE was completed, a research assistant conducted a follow-up investigation in the same way as the pretest. To verify identity at pretest and posttest, the questionnaire contains an email address as a record entry.

\section{Ethical Considerations}

This study was carried out after the deliberation of the Institutional Review Boards (IRB) of the university where the researcher is associated (IRB No. 1041478-201302-HR003). We explained the purpose of the research; the confidentiality; the voluntary participation in the research; and the right to withdraw participation at any point, and the right to refuse to fill out questionnaire on own will even while participating in the study based on the informed consent form. Afterwards, we collected written consent from all the students for their participation. A research assistant who had no direct relationship with the research students collected the participation consent forms and surveys, in order to minimize any possible impact on the research results. As ethical consideration, after completion of the study, the SBE group was given the same reading materials and IRAT that were distributed to the SBE combined TBL group and the tutor had time to solve IRAT questions and explain them for about 1 hour.

\section{Data Analysis}

The collected data were analyzed with IBM Statistics SPSS $^{\circledast}$ version 22.0. For the homogeneity tests between the SBE combined TBL and SBE groups, $x^{2}$ and t-tests were conducted. To compare self-directed learning, communication skills and team efficacy between the two groups, independent $t$-test was performed. To compare nursing performance confidence score in two groups, ANCOVA was performed due to homogeneity test's result.

\section{RESULTS}

\section{Homogeneity Test}

Table 1 shows the general characteristics of the SBE combined TBL group and the SBE group and the results of verifying the homogeneity of the variables. There were no differences between the SBE combined TBL and SBE groups in age, gender, or experience with stroke or myocardial infarction patients. Additionally, there was no difference between the SBE combined TBL and SBE groups in experience with techniques including vital monitoring, IV injection, indwelling urethral catheter, transfusion, and ECG and oxygen saturation monitoring. The average rating was used for self-directed learning, communication skills, nursing performance confidence and team efficacy score. There were also no differences between the groups in self-directed learning, communication skills, or team efficacy scores $(\mathrm{t}=0.73, p=.464 ; \mathrm{t}=0.52, p=.605 ; \mathrm{t}=-1.75, p=.082)$. However, nursing performance confidence scores showed differences, with $3.80 \pm 0.50$ for the SBE combined TBL group and $3.64 \pm 0.42$ for the SBE group $(\mathrm{t}=2.33 . p=.021)$ (Table 1$)$.

\section{Difference in Variables between SBE Combined TBL Group and SBE Group}

When it comes to the self-directed learning score, while the SBE combined TBL group had $3.48 \pm 0.51$ at pretest, $3.58 \pm 0.47$ at posttest with a mean difference of $0.09 \pm 0.71$, the SBE group had $3.43 \pm 0.42$ at pretest, $3.42 \pm 0.39$ at posttest with a mean difference of $-0.01 \pm 0.53$ so that there was no statistical significance in differences $(\mathrm{t}=-1.10, p=.274)$. When it comes to the communication skills score, while the SBE combined TBL group had $3.62 \pm 0.35$ at pretest, $3.60 \pm 0.36$ at posttest and with a difference of $-0.01 \pm 0.47$, the SBE group had $3.59 \pm 0.35$ at pretest, $3.40 \pm 0.35$ at posttest with a difference of $-0.19 \pm 0.51$ so that there was a significant difference between the groups $(\mathrm{t}=2.45, p=.015)$. For nursing performance confidence score, the SBE combined TBL group had $3.80 \pm 0.50$ at pretest, $3.95 \pm 0.52$ at posttest with a difference of $0.16 \pm 0.68$, while the SBE group had $3.64 \pm 0.42$ at pretest, $3.79 \pm 0.49$ at posttest with a difference of $0.15 \pm 0.66$ so that there was a significant difference between the groups $(\mathrm{F}=4.30, p=.040)$. For the team efficacy score, the SBE combined TBL group had $4.02 \pm 0.59$ at pretest, $4.16 \pm 0.69$ at posttest with a difference of $0.14 \pm$ 0.89 , and the SBE group had $4.17 \pm 0.54$ at pretest, $3.93 \pm$ 0.63 at posttest with a difference of $-0.24 \pm 0.79$ so that there was a significant difference between the groups $(t=3.06$, $p=.003$ )(Table 2). 
Table 1. Homogeneity Test between SBE Combined TBL Group and SBE Group

$(N=181)$

\begin{tabular}{|c|c|c|c|c|c|}
\hline \multirow[t]{2}{*}{ Variables } & \multirow[t]{2}{*}{ Categories } & \multirow{2}{*}{$\begin{array}{l}\text { SBE combined TBL } \\
\text { group }(\mathrm{n}=84) \\
\mathrm{n}(\%) \text { or } \mathrm{M} \pm \mathrm{SD}\end{array}$} & \multirow{2}{*}{$\begin{array}{c}\begin{array}{c}\text { SBE group } \\
(\mathrm{n}=97)\end{array} \\
\mathrm{n}(\%) \text { or } \mathrm{M} \pm \mathrm{SD} \\
\end{array}$} & \multirow[t]{2}{*}{$x^{2}$ or $\mathrm{t}$} & \multirow{2}{*}{$p$} \\
\hline & & & & & \\
\hline Age (year) & & $22.88 \pm 0.78$ & $23.33 \pm 1.24$ & 13.21 & .067 \\
\hline Gender & $\begin{array}{l}\text { Female } \\
\text { Male }\end{array}$ & $\begin{array}{c}80(95.2) \\
4(4.8)\end{array}$ & $\begin{array}{c}89(91.8) \\
8(8.2)\end{array}$ & 0.88 & .387 \\
\hline $\begin{array}{l}\text { Experience of observation } \\
\text { in stroke patient care }\end{array}$ & $\begin{array}{l}\text { Yes } \\
\text { No }\end{array}$ & $\begin{array}{l}35(41.7) \\
49(58.3)\end{array}$ & $\begin{array}{l}30(30.9) \\
67(69.1)\end{array}$ & 2.26 & .162 \\
\hline $\begin{array}{l}\text { Experience of observation } \\
\text { in MI patient care }\end{array}$ & $\begin{array}{l}\text { Yes } \\
\text { No }\end{array}$ & $\begin{array}{l}30(35.7) \\
54(64.3)\end{array}$ & $\begin{array}{l}30(30.9) \\
67(69.1)\end{array}$ & 0.47 & .529 \\
\hline \multicolumn{6}{|c|}{ Nursing skill experience in prior clinical practicum } \\
\hline Vital signs & $\begin{array}{l}\text { Experience of observation } \\
\text { Experience of performance }\end{array}$ & $\begin{array}{c}7(8.3) \\
77(91.7)\end{array}$ & $\begin{array}{l}15(15.5) \\
82(84.5)\end{array}$ & 2.14 & .174 \\
\hline IV infusion & $\begin{array}{l}\text { Experience of observation } \\
\text { Experience of performance }\end{array}$ & $\begin{array}{r}75(89.3) \\
9(10.7)\end{array}$ & $\begin{array}{l}87(89.7) \\
10(10.3)\end{array}$ & 0.01 & .997 \\
\hline Indwelling catheterization & $\begin{array}{l}\text { Experience of observation } \\
\text { Experience of performance } \\
\text { No experience }\end{array}$ & $\begin{array}{c}73(86.9) \\
5(6.0) \\
6(7.1)\end{array}$ & $\begin{array}{c}86(88.6) \\
4(4.2) \\
7(7.2)\end{array}$ & 0.32 & .853 \\
\hline Blood transfusion & $\begin{array}{l}\text { Experience of observation } \\
\text { Experience of performance } \\
\text { No experience }\end{array}$ & $\begin{array}{c}78(92.8) \\
1(1.2) \\
5(6.0)\end{array}$ & $\begin{aligned} 83 & (85.6) \\
2 & (2.0) \\
12 & (12.4)\end{aligned}$ & 2.45 & .294 \\
\hline Oxygen therapy & $\begin{array}{l}\text { Experience of observation } \\
\text { Experience of performance }\end{array}$ & $\begin{array}{l}40(47.6) \\
44(52.4)\end{array}$ & $\begin{array}{l}51(52.6) \\
46(47.4)\end{array}$ & 0.44 & .552 \\
\hline ECG monitoring & $\begin{array}{l}\text { Experience of observation } \\
\text { Experience of performance }\end{array}$ & $\begin{array}{l}53(63.1) \\
31(36.9)\end{array}$ & $\begin{array}{l}61(62.9) \\
36(37.1)\end{array}$ & 0.01 & .997 \\
\hline Certification related CPR & $\begin{array}{l}\text { Have } \\
\text { Have not }\end{array}$ & $\begin{array}{c}80(95.2) \\
4(4.8)\end{array}$ & $\begin{array}{l}96(99.0) \\
1(1.0)\end{array}$ & 2.33 & .184 \\
\hline Self-directed learning & & $3.48 \pm 0.51$ & $3.43 \pm 0.42$ & 0.73 & .464 \\
\hline Communication skills & & $3.62 \pm 0.35$ & $3.59 \pm 0.35$ & 0.52 & .605 \\
\hline Nursing performance confidence & & $3.80 \pm 0.50$ & $3.64 \pm 0.42$ & 2.33 & .021 \\
\hline Team efficacy & & $4.02 \pm 0.59$ & $4.17 \pm 0.54$ & -1.75 & .082 \\
\hline
\end{tabular}

SBE combined TBL=Simulation-based education combined team-based learning; SBE=Simulation based education; MI=Myocardial infarction; $\mathrm{IV}=$ Intravenous; $\mathrm{ECG}=$ Electrocardiogram; $\mathrm{CPR}=$ Cardiopulmonary resuscitation.

Table 2. Comparison for Mean Scores of Variables between SBE Combined TBL Group and SBE Group

$(N=181)$

\begin{tabular}{|c|c|c|c|c|c|c|}
\hline \multirow{2}{*}{ Variables } & \multirow{2}{*}{ Group } & Pretest & Posttest & Difference & \multirow{2}{*}{$\mathrm{t}$ or $\mathrm{F}$} & \multirow{2}{*}{$p$} \\
\hline & & $\mathrm{M} \pm \mathrm{SD}$ & $\mathrm{M} \pm \mathrm{SD}$ & $\mathrm{M} \pm \mathrm{SD}$ & & \\
\hline \multirow{2}{*}{$\begin{array}{l}\text { Self-directed } \\
\text { learning }\end{array}$} & SBE combined TBL group & $3.48 \pm 0.51$ & $3.58 \pm 0.47$ & $0.09 \pm 0.71$ & \multirow[t]{2}{*}{-1.10} & \multirow[t]{2}{*}{.274} \\
\hline & SBE group & $3.43 \pm 0.42$ & $3.42 \pm 0.39$ & $-0.01 \pm 0.53$ & & \\
\hline \multirow{2}{*}{$\begin{array}{l}\text { Communication } \\
\text { skills }\end{array}$} & SBE combined TBL group & $3.62 \pm 0.35$ & $3.60 \pm 0.36$ & $-0.01 \pm 0.47$ & \multirow[t]{2}{*}{2.45} & \multirow[t]{2}{*}{.015} \\
\hline & SBE group & $3.59 \pm 0.35$ & $3.40 \pm 0.35$ & $-0.19 \pm 0.51$ & & \\
\hline \multirow{2}{*}{$\begin{array}{l}\text { Nursing performance } \\
\text { confidence }\end{array}$} & SBE combined TBL group & $3.80 \pm 0.50$ & $3.95 \pm 0.52$ & $0.16 \pm 0.68$ & \multirow[t]{2}{*}{4.30} & \multirow[t]{2}{*}{$040^{\circ}$} \\
\hline & SBE group & $3.64 \pm 0.42$ & $3.79 \pm 0.49$ & $0.15 \pm 0.66$ & & \\
\hline \multirow[t]{2}{*}{ Team efficacy } & SBE combined TBL group & $4.02 \pm 0.59$ & $4.16 \pm 0.69$ & $0.14 \pm 0.89$ & \multirow[t]{2}{*}{3.06} & \multirow[t]{2}{*}{.003} \\
\hline & SBE group & $4.17 \pm 0.54$ & $3.93 \pm 0.63$ & $-0.24 \pm 0.79$ & & \\
\hline
\end{tabular}

*F values by ANCOVA with pretest score of nursing performance confidence as covariate; SBE combined TBL=Simulation-based education combined team-based learning; $\mathrm{SBE}=$ Simulation based education. 
Table 3. Comparison for Team Performance Scores between SBE Combined TBL Group and SBE Group

\begin{tabular}{|c|c|c|c|c|}
\hline \multirow[t]{2}{*}{ Variables } & $\begin{array}{l}\text { SBE combined TBL group } \\
\qquad(\mathrm{n}=84)\end{array}$ & $\begin{array}{l}\text { SBE group } \\
(\mathrm{n}=97)\end{array}$ & \multirow[t]{2}{*}{$\mathrm{t}$} & \multirow[t]{2}{*}{$p$} \\
\hline & $\mathrm{M} \pm \mathrm{SD}$ & $\mathrm{M} \pm \mathrm{SD}$ & & \\
\hline Team performance score & $32.93 \pm 1.33$ & $31.44 \pm 0.85$ & 8.77 & $<.001$ \\
\hline Module 1 team performance score & $32.92 \pm 1.30$ & $30.37 \pm 1.53$ & 12.00 & $<.001$ \\
\hline Module 2 team performance score & $32.95 \pm 1.33$ & $31.56 \pm 0.88$ & 8.14 & $<.001$ \\
\hline
\end{tabular}

SBE combined TBL=Simulation-based education combined team-based learning; SBE=Simulation based education

\section{Difference in Team Performance Score between SBE Combined TBL Group and SBE Group}

The team performance score for the SBE combined TBL group was $32.93 \pm 1.33$ and $31.44 \pm 0.85$ for the SBE group. The SBE combined TBL group showed a higher team performance score compared to SBE group. It was significant $(\mathrm{t}=8.77, p<.001)$ (Table 3$)$.

\section{DISCUSSION}

Existing TBL methodologies have been used mainly in theoretical sessions and many simulation studies have been performed on a small-group basis. However, this study differentiates itself from other studies in that it applies SBE combined TBL on clinical practice sessions with nursing students, based on the nursing education simulation and the team-based learning models. SBE combined TBL may be an effective simulation learning program that enables participants to practice nursing care to resolve complex nursing problems in clinical situations. Students, through the specific clinical cases, would be able to share the thinking processes of nursing with colleagues to resolve problems and improve their clinical performance ability. Therefore, this study applied SBE combined TBL to the nursing students, and compared its effectiveness with a SBE.

When it comes to the self-directed learning score, while the SBE combined TBL group had $0.09 \pm 0.71$ in the difference between pretest and posttest, the SBE group had $-0.01 \pm 0.53$ so that there was no statistical significant difference between the groups. This is similar to the result of a study applying PBL combined simulation [4]. As it was expected though, the students in SBE combined TBL group would bring up diverse questions on their own, share, appraise, and apply information and ideas through interaction within groups, so that a more mature thinking process can be experienced [7,11], the result showed that higher self-directed learning scores were observed compared to the SBE group. However, in this study, the self-directed learning scores between the groups showed no significant difference. In many simulation studies, the results of the self-directed learning differ from one study to the next and the meta-analysis result showed that the effect size was not large enough [6]. It is believed because self-directed learning is hard to get used to in a short period of time. As self-directed learners have characteristics such as attachment to learning, self-confidence as a learner, openness to challenge and acceptance of responsibility for learning, it is necessary to consider such characteristics of these learners when designing lessons to enhance learner's self-directed learning [22]. The SBE combined TBL applied in this study may reflect these characteristics during the IRAT and GRAT process, and supports the results that TBL increases the learners' self-directed learning abilities $[12,13]$. In future studies, repeated research and long-term trends in self-directed learning with SBE combined TBL should be tracked.

Second, when it comes to the communication skills score, while the SBE combined TBL group had $-0.01 \pm 0.47$ in the difference between pretest and posttest, the SBE group had $-0.19 \pm 0.51$ so that there was a significant difference between groups. For improvement in communication skill, therapeutic communication was recommended for use when communicating with SP and high-fidelity simulator, but no additional training was provided. Therefore, in order to improve communication skills through future simulation training, specific strategies for SBAR communication or therapeutic communication should be included.

Also, in this study, the communication skills score for the SBE combined TBL group should be higher than the SBE group, however in both groups, communication scores were lower than before the simulation education. A simulation education using high fidelity simulator and SP was carried out and it was designed to have a favorable response in the high fidelity simulation and a non-favorable response in the simulation using the SP. The simulation practice with SP can enhance the reality of communication better than high fidelity simulator and the favorable re- 
sponse of the patient may also have a positive learning effect on the students [23] and the simulation practice using SP has been shown to cause some students to feel fear and anxiety [24]. The SP in this study was in a senior-junior relationship with the students and showed some unfavorable reactions to the students' nursing, and these factors seemed to increase the burden of learner, which lowered the communication scores. Therefore, it is necessary to consider these factors when selecting SP in the future. Results of studies using many high-fidelity simulators have showed positive effects of communication skills, but this is likely to vary depending on simulation scenarios and environments so that it is necessary to identify with the content aspect of the class when determining the effectiveness of communication skills. In addition, a detailed analysis of how the patient's reaction in the simulation situation affects the learning effect is necessary and a study comparing the SP with the high fidelity simulator is also necessary.

Third, when it comes to the nursing performance confidence, while the SBE combined TBL group had 0.16士 0.68 in the difference between pretest and posttest, the SBE group had $0.15 \pm 0.66$ so that there was a significant difference between the groups. The positive effects of simulation based education have been consistently reported in both domestic and overseas settings, in terms of the enhancement in clinical skills, clinical competency, and confidence $[25,26]$. Simulation combined TBL has not been widely applied so that it is difficult to make a direct comparison. It supports the research result that the group applying the TBL simulation had a high clinical performance compared to the control group which performed clinical practices and technical training in the laboratory [6]. SBE combined TBL has been confirmed to be an effective learning methodology to improve nursing performance confidence and team performance score. However, in this study, pre homogeneity was not made between experimental group and control group in the case of nursing performance confidence so that ANCOVA was performed after nursing performance confidence was set as covariate. Although there was a statistically significant difference between the two groups in the result, the score difference between the pretest and the posttest in each group was small and homogeneity was not obtained in advance so that a careful attention should be paid to expanding the results of the study.

Lastly, when it comes to the team efficacy, while the SBE combined TBL group had $0.14 \pm 0.89$ in the difference between pretest and posttest, the SBE group had $-0.24 \pm 0.79$ so that there was a significant difference between groups.
The team efficacy score for the SBE combined TBL group should show higher than the SBE group. Also the team efficacy score in the SBE group was lower than the one before the simulation training. Team efficacy becomes a source of positive team performance in team learning activities, and it is closely related to the attitude of support and cooperation among team members [19]. In particular, team work processes are important factors in sharing information among team members [27] and allow nurses to function effectively in actual situations that require acting as a team [28]. Until now, many simulation studies confirmed the self-efficacy of the students and but self-efficacy did not have an adequate effect size [2]. Only two studies confirmed team efficacy [3]. One study [6] found that team efficacy increased after simulation education and another study [29] said that it was not statistically significant. Team configuration becomes an important factor. A team made of heterogeneous learners can enhance the team performance by maximizing the interaction among the various characteristics of each individual., However, lack of mutual trust and understanding among team members can adversely affect team activity itself, therefore it is imperative to have a mechanism of belief that respects the diversity of individuals and ties them together into one team, and team building activities are needed to build mutual confidence [27]. The important thing about team building is to allow members to share a clear sense of purpose. Two groups in this study were randomly composed by picking straws and while no team building activity was undertaken, SBE combined TBL group had a common goal of receiving a high GRAT score and it is believed that this common goal had a positive impact on the team-efficacy score. Researchers are required to focus on the study of team efficacy in future simulation team activities and the team activities in general nursing education courses. Team efficacy is thought to be influenced by the team building activities. Therefore, future studies need to include more dynamic activities for team building considering learning methodology, abilities and personalities.

These conclusions so far, imply that there is a need to devise diverse strategies for nursing education in a time when the clinical environment is becoming more demanding, and we believe that the SBE combined TBL introduced in this study may be a valid option. There were some limitations to this study. Firstly, because the study was conducted as a convenience sample from one university so that insufficiencies in the university's educational program might have been reflected in the results of the study, it limits the ability to generalize the results to other populations. Second, in order to ensure the homogeneity of the 
groups and to verify the effectiveness of SBE combined TBL, uniformity was ensured in terms of the nursing skills that each student had learned in pervious clinical practices. The students had learned about nursing care for stroke and myocardial infarction patients in an adult nursing course during the second semester of their junior year, therefore no separate knowledge pre-test was done, in assumption that all students would have similar knowledge. Therefore, in future studies, homogeneity should be secured by checking not only the experience in nursing techniques but also the background knowledge level.

\section{CONCLUSION}

Simulation-based education combined TBL could be an effective methodology compared to SBE in order to improve nursing students' positive educational outcomes, all of which are required skills in dynamic clinical situations. We would like to suggest the following recommendations, based on the results of this study. First, in order to enhance self-directed learning, plentiful simulation-based education programs should be designed including diverse clinical situation scenarios. Second, we suggest the development of an integrated course with both theory sessions and simulation practice sessions based on SBE combined TBL.

\section{REFERENCES}

1. Harden RM. Looking back to the future: A message for a new generation of medical educators. Medical Education. 2011;45 (8):777-784. http://dx.doi.org/10.1111/j.1365-2923.2011.03934.x

2. Kim SH, Ham Y. A meta-analysis of the effect of simulation based education -Korean nurses and nursing students-. Journal of Korean Academic Society of Nursing Education. 2015, 21(3):308-319.

3. Kim JH, Park IH, Shin S. Systemic review of Korean studies on simulation within nursing education. Journal of Korean Academic Society of Nursing Education. 2013;19(3):307-319.

4. Lee WS, Cho KC, Yang SH, Roh YS, Lee GY. Effects of problem-based learning combined with simulation on the basic nursing competency of nursing students. Journal of Korean Academy of Fundamentals of Nursing. 2009;16(1):64-72.

5. Song YA. Effect of simulation-based practice by applying problem based learning on problem solving process, self-confidence in clinical performance and nursing competence. Korean Journal of Women Health Nursing. 2014;20(4):246-254.

6. Kim HR, Choi EY, Kang HY. Simulation module development and team competency evaluation. Journal of Korean Academy of Fundamentals of Nursing. 2011;18(3):392-400.

7. Michaelsen LK, Knight AB, Fink LD. Team-based learning: A transformative use of small groups. 1st ed. Lee YM, Jun DK, translator. Wesport, CT: Greenwood Publishing Group; 2009.

8. Han SJ. The impact of TBL (team-based learning) on nursing students. Journal of Digital Policy \& Management. 2013;11(11): 595-602.

9. Park $\mathrm{KH}$, Park $\mathrm{CH}$, Chung WJ, Yoo CJ. Implementation of problem-based learning combined with team-based learning. Korean Journal of Medical Education. 2010:22(3):225-230. http://dx.doi.org/10.3946/kjme.2010.22.3.225

10. Lee YM, Nam JK, Cho SY, Lee SY. The effects of team-based learning on learners' performance, learning activities, and motivation in a vocational high school. Journal of Vocational Education Research. 2011;30(2):51-71.

11. Roh YS, Ryoo EN, Choi D, BaekS, Kim SS. A survey of student perceptions, academic achievement, and satisfaction of teambased learning in a nursing course. Journal of Korean Academic Society of Nursing Education. 2012;18(2):239-247.

12. Lim SH. Effects of team-based learning on anatomy subject for biological nursing science education of nursing students. Journal of the Korea Academica-Industrial Cooperation Society. 2015;16(10):7098-7108.

13. Choi KO, Park YM. The effects of team-based learning on problem solving ability, critical thinking disposition and self-directed learning in undergraduate students. Journal of East-West Nursing Research. 2014;20(2):154-159.

14. Lee SK, Kim SH, Park SN. Persistence of integrated nursing simulation program effectiveness. Journal of Korean Academy of Fundamentals of Nursing. 2016;23(3):283-291.

15. Park SN, Chu MS, Hwang YY, Kim SH, Lee SK. Effects of integrated nursing practices simulation-based training on stress, interest in learning, and problem-solving ability of nursing students. Journal of Korean Academy of Fundamentals of Nursing. 2015;22(4):424-432.

16. Jeffries PR. A framework for designing, implementing, and evaluating simulations used as teaching strategies in nursing. Nursing Education Perspectives. 2005;26(2):96-103.

17. Lee SJ, Chang YK, Lee HN, Park KY. A study on development of life-skills: Communication, problem solving, and self-directed learning. Research Report. Seoul: Korean Educational Development Institute; 2003 December. Report No.: RR 201315-3

18. Yang JJ, Park MY. The relationship of clinical competence and self-directed learning in nursing students. Journal of Korean Academy Society Nursing Education. 2004;10:271-277.

19. Marshall LC. The relationship between efficacy, team-work, effort and patient satisfaction [dissertation]. Los Angeles: University of Southern California; 2003. p.1-191.

20. Kwon EM. The correlation among team efficacy, interpersonal 
understanding, proactivity in problem solving and team performance [master's thesis]. Seoul: Ewha Womans University; 2010. p.1-82.

21. Kim MY, Park S, Won J. Influence of nursing students' anxiety during simulation training on personal satisfaction of simulation, self-efficacy, clinical competence. Journal of Korean Academy of Fundamentals of Nursing. 2016:23(4):411-418. http://dx.doi.org/10.7739/jkafn.2016.23.4.411

22. Benedict N, Schonder K, McGee J. Promotion of self-directed learning using virtual patient cases. American Journal of Pharmaceutical Education. 2013;77(7):151. http://dx.doi.org/10.5688/ajpe777151

23. Kang HY, Choi EY, Kim HR. Nursing student's experience in team based simulation learning. Journal of Korean Academic Society of Nursing Education. 2013;19(1):5-15.

24. Yoo MS, Yoo IY, Son YJ. The effectiveness of standardized patient managed instruction in teaching foley catheterization skills, communication skills and learning motivation. Journal of Korean Academy of Fundamentals of Nursing. 2002;9(1): 66-75.

25. Cant RP, Cooper SJ. Simulation-based learning in nurse educa- tion: systematic review. Journal of Advanced Nursing. 2010; 66(1):3-15.

26. Lapkin S, Levett-Jones T, Bellchambers H, Fernandez R. Effectiveness of patient simulation manikins in teaching clinical reasoning skills to undergraduate nursing students: A systematic review. Clinical Simulation in Nursing. 2010;6(6): e207-e222. http://dx.doi.org/10.1016/j.ecns.2010.05.005

27. Cummings JN. Work groups, structural diversity, and knowledges sharing in a global organization. Management Science. 2004;50(3):352-364.

http://dx.doi.org/10.1287/mnsc.1030.0134

28. Dietz AS, Pronovost PJ, Mendez-Tellez PA, Wyskiel R, Marsteller JA, Thompson DA, et al. A systematic review of teamwork in the intensive care unit: What do we know about teamwork, team tasks, and improvement strategies? Journal of Critical Care. 2014;29(6):908-914.

29. Jun HY, ChoYI, Park KE, Kim JM. Effect of human patient simulator-based education on self-directed learning and collective efficacy. The Journal of the Korea Contents Association. 2012; 12(5):293-302. 